\title{
Improved Prediction Model for Determining the Lost Gas Content of Extreme-soft and Outburst-prone Coal Seam
}

\author{
Xu Dong-fang ${ }^{1, *}$, Feng Tao ${ }^{2}$, Qin Zuo-ya ${ }^{3}$ and Yang Jing ${ }^{3}$ \\ ${ }^{I}$ Central South University/Hunan Provincial Coal Science Research Institute, Hunan Changsha 410004, China; \\ ${ }^{2}$ Central South University/Hunan University of Science and Technology, Hunan Xiangtan 411201, China; ${ }^{3}$ Hunan \\ Provincial Coal Science Research Institute, Hunan Changsha 410004, China
}

\begin{abstract}
Few study has been carried out on the desorption rules of extreme-soft and outburst-prone coal in south of China, especially coal from Hunan Province of which the value of " $\mathrm{f}$ " is normally less than 0.2 . Desorption experiments are conducted on the coal samples from Hongwei and Jiahe Mines in Hunan Province, and the following phenomena can be observed: the calculating mean error by $\sqrt{\mathrm{t}}$ method and power function method of Hongwei coal samples are $29.68 \%$ and $68.33 \%, 28.55 \%$ and $70.28 \%$ of Jiahe , the calculating result by the two methods is always lower. After comparison we find that the $\sqrt{t}$ method is more precise than power function method, so calculation method is improved based on $\sqrt{t}$ method, mean error of gas content determination by the new method in experiment and coal mine are $6.88 \%$ and $5.24 \%$, both less than $10 \%$.
\end{abstract}

Keywords: $\sqrt{\mathrm{t}}$ method, extreme-soft, improved $\sqrt{\mathrm{t}}$ method, lost gas content, outburst-prone coal seam, power function method.

\section{INTRODUCTION}

One of the most important indexes to predict outburstprone of coal seam is gas content of which the measurement result can reflect safety of coal mine directly [1]. In the current calculation method, gas content includes three parts: lost gas content, desorption gas content and residual gas content. Both desorption gas content and residual gas content can be measured precisely, but there is great error on the lost gas content which is calculated by desorption rules, so it is significant important to know about the desorption rules of gas in coal seam. Some researches on desorption rules of gas in general coal seam have been done both home and aboard and so some models have been found, however, few study has been carried out on the desorption rules of gas in extremesoft and outburst prone coal seam. Much of coal seam of Hunan province is tectonic coal, according to the research we find that the result of lost gas content calculated by standard model is always lower and so lead to lower gas content measurement result which could not reflect the outburstprone effected [2], so it is necessary to do some research on this kind of coal seam in order to improve the calculation model.

\section{EXPERIMENT DESIGN}

\subsection{Experiment System Design}

In order to know about the desorption rules of extremesoft and outburst-prone coal seam, we designed the Adsorption and Desorption Experiment System which mainly include high pressure gas charging unit, temperature control

\footnotetext{
*Address correspondence to this author at the Central South University/Hunan Provincial Coal Science Research Institute, Hunan Changsha 410004, China; E-mail: xudongfang@csu.edu.cn
}

unit, vacuum pump unit and desorption rate measurement unit [3], as shown in Fig. (1).

\subsection{Sample Made}

The coal samples of Hunan Hongwei coal mine (recorded as HW) and Jiahe Puxi coal mine (recorded as JH) are made to five different sizes $(<0.2 \mathrm{~mm}, \quad 0.2 \mathrm{~mm} \sim 0.5 \mathrm{~mm}$, $0.5 \mathrm{~mm} \sim 1 \mathrm{~mm}, 1 \mathrm{~mm} \sim 3 \mathrm{~mm},>3 \mathrm{~mm})$, each of the sample should be more than $1000 \mathrm{~g}$.

\subsection{Steps of Experiment}

(1) Get one of the sample (about 600g) and put it into drying oven whose temperature is set to $100^{\circ} \mathrm{C}$ and take it out one hour later, then put the dried coal into pot as much as possible to reduce the dead space. Seal the pot at last.

(2) Vacuum pump the coal sample pot under $60^{\circ} \mathrm{C} \pm 1{ }^{\circ} \mathrm{C}$ until the pressure in it fall to $10 \mathrm{~Pa}$ and then turn off the vacuum pump and valve which is used to connect vacuum pump and pot.

(3) After vacuum pumping, connect the coal sample pot to gas cylinder and then open all valves to let the gas come into pot until the pressure in it rise to 1.5 times than the equilibrium pressure, and then keep the pot in thermostatic bath whose temperature is set to $30^{\circ} \mathrm{C} \pm 1^{\circ} \mathrm{C}$ for 24-48 hours.

(4) In the desorption experiment, we set the temperature of thermostatic bath to $23^{\circ} \mathrm{C} \pm 1{ }^{\circ} \mathrm{C}$, test and record temperature of air and water, atmosphere, prepare stopwatch and desorption instrument, connect pipeline and then open the valve to let the desorption gas come into the measuring cylinder, open the glass valve of $800 \mathrm{ml}$ measuring cylinder while pressure in the pot close to zero 


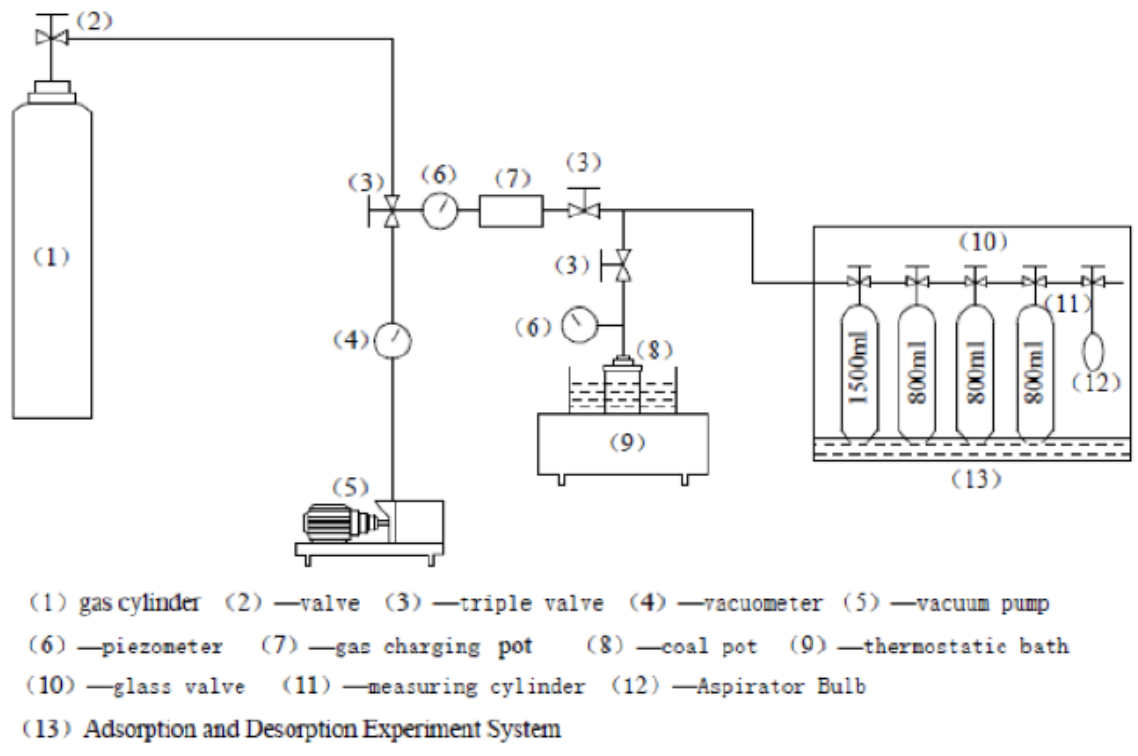

Fig. (1). Schematic of gas adsorption-desorption apparatus.

and start stopwatch at the same time, record desorption volume every 20-60s according to the desorption rate.

(5) In order to compare the desorption rules of different samples, we should transform the tested desorption volume in experiment to standard according to the following formula:

$$
V_{t}=\frac{273.2}{101325\left(273.2+t_{w}\right)}\left(P_{a t m}-9.81 h_{w}-P_{S}\right) \cdot V_{t}^{\prime}
$$

In formula: $V \mathrm{t}$ - Total gas desorption of standard condition, $\mathrm{cm} 3 ; V_{t}^{\prime}$-Measured total gas desorption under the experiment environment, $\mathrm{cm} 3$; tw-Water temperature of the burette, ${ }^{\circ} \mathrm{C}$; Patm-Atmospheric pressure, Pa; hw-Watercolumn of the burette when reading data, $\mathrm{mm}$; PSSaturated steam pressure under tw, $\mathrm{Pa}$.

\section{FOUNDATION OF IMPROVED CALCULATION MODEL OF LOST GAS CONTENT}

\subsection{Filter of Calculation Model}

A lot of researches on the calculation model of lost gas content have been done both home and aboard during the latest thirty years and so some models were found, such as $\sqrt{t}$ method, Went formula, Uz. But formula, England empirical formula, Botte formula, Exponential function method, Wang Youan formula and Sun Chongxu formula [4-14]. Those methods could be classified to two kinds of formula, one is power function, like $\sqrt{t}$ method, Went formula, Uz. But formula, Wang Youan formula and Sun Chongxu formula; the other is exponential function, such as Botte formula, Exponential function method $[15,16]$. According to study and after comparison, some researchers think that the $\sqrt{\mathrm{t}}$ method based on desorption volume and the power function method based on desorption rate could determine lost gas content more precisely (the formula of $\sqrt{t}$ method is $Q_{\mathrm{t}}=K \cdot \sqrt{\mathrm{t}_{0}+\mathrm{t}}+Q_{\text {损, }}$ and the power function method is $\left.\mathrm{q}_{\mathrm{t}}=\mathrm{q}_{0}(1+\mathrm{t})^{-\mathrm{n}}\right)$. In this paper, experiment on extreme-soft and outburst-prone coal samples has been done in order to compare accuracy of lost gas content determined by $\sqrt{t}$ method and power function method, and finally improve the prediction model.

\subsection{Error Analysis of Calculation Models}

By experiment we get the desorption rate data of coal samples made before under $1 \mathrm{MPa}, 2 \mathrm{MPa}$ and $3 \mathrm{MPa}$ equilibrium pressure condition, after comparison we choose these data (1 $\mathrm{MPa}$ and $2 \mathrm{MPa}$ ) to analyze the error of lost gas content calculated by $\sqrt{\mathrm{t}}$ method and power function method. The result of analysis was shown in Table $\mathbf{1}$ and $\mathbf{2}$.

According to Table $\mathbf{1}$ and $\mathbf{2}$, following phenomena can be observed:

(1) The error of lost gas content calculated by $\sqrt{t}$ method of HW coal samples is $25.00 \% \sim 35.71 \%$, the mean error is $29.68 \%$, and $\mathrm{JH}$ coal samples is $22.60 \% \sim 34.05 \%$ and $28.55 \%$.

(2) The error of lost gas content calculated by power function method of HW coal samples is $65.54 \% \sim 71.05 \%$, the mean error is $68.33 \%$, and $\mathrm{JH}$ coal samples is $66.80 \% \sim 73.26 \%$ and $70.28 \%$. After comparison, we find the error caused by power function method is bigger than which caused by $\sqrt{\mathrm{t}}$ method.

(3) Lost gas content calculated by both $\sqrt{t}$ method based on desorption volume and power function method based on desorption rate is always lower.

(4) According to the experiment result, the error of lost gas content calculated by $\sqrt{\mathrm{t}}$ method is lower than which calculated by power function method under the same condition, that means $\sqrt{\mathrm{t}}$ method is more precise.

\subsection{Foundation of Improved Prediction Model}

$\sqrt{\mathrm{t}}$ Method is more precise than power function method in calculating lost gas content; however, the error caused by this kind of method is up to $30 \%$, so unavoidably it always 
Table1. Errors by the two methods under equilibrium gas pressure $1 \mathrm{MPa}$.

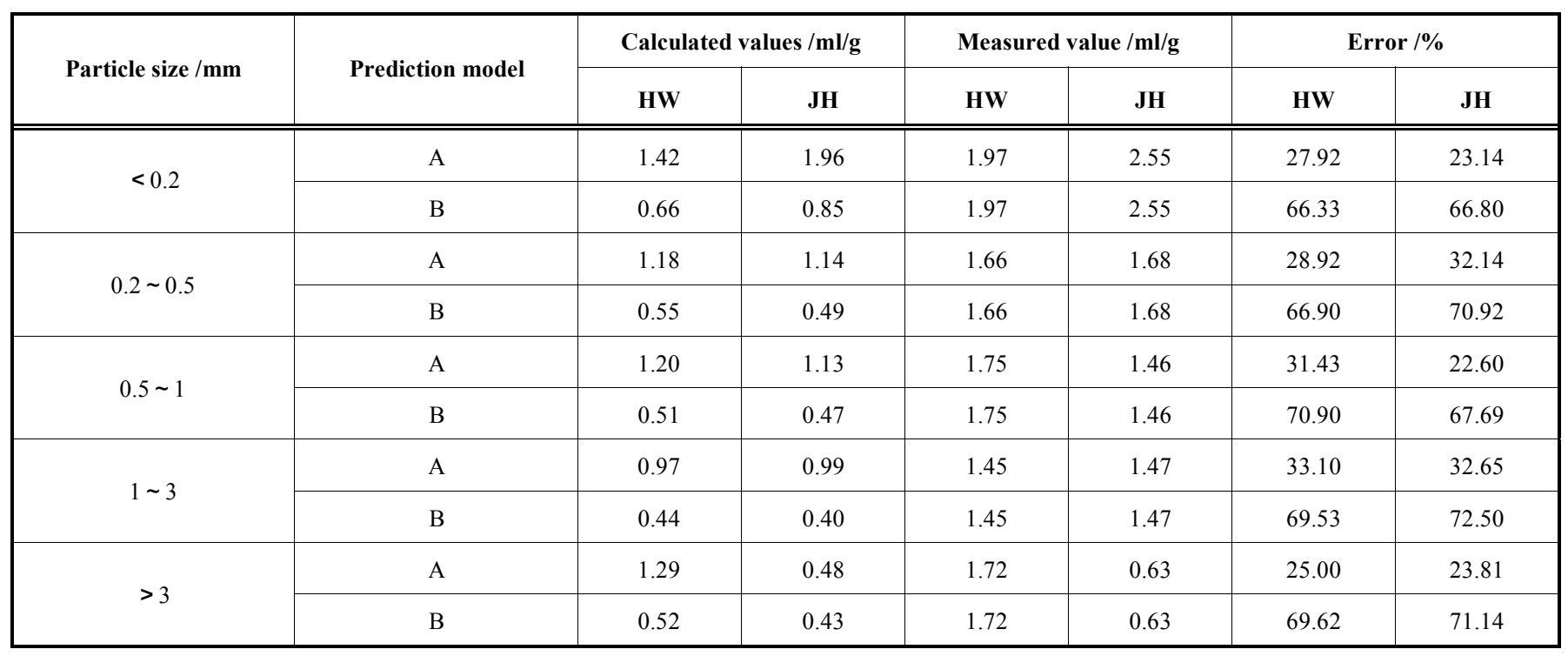

A: $\sqrt{t}$ method, B: power function method.

Table 2. Errors by the two methods under equilibrium gas pressure $3 \mathrm{MPa}$.

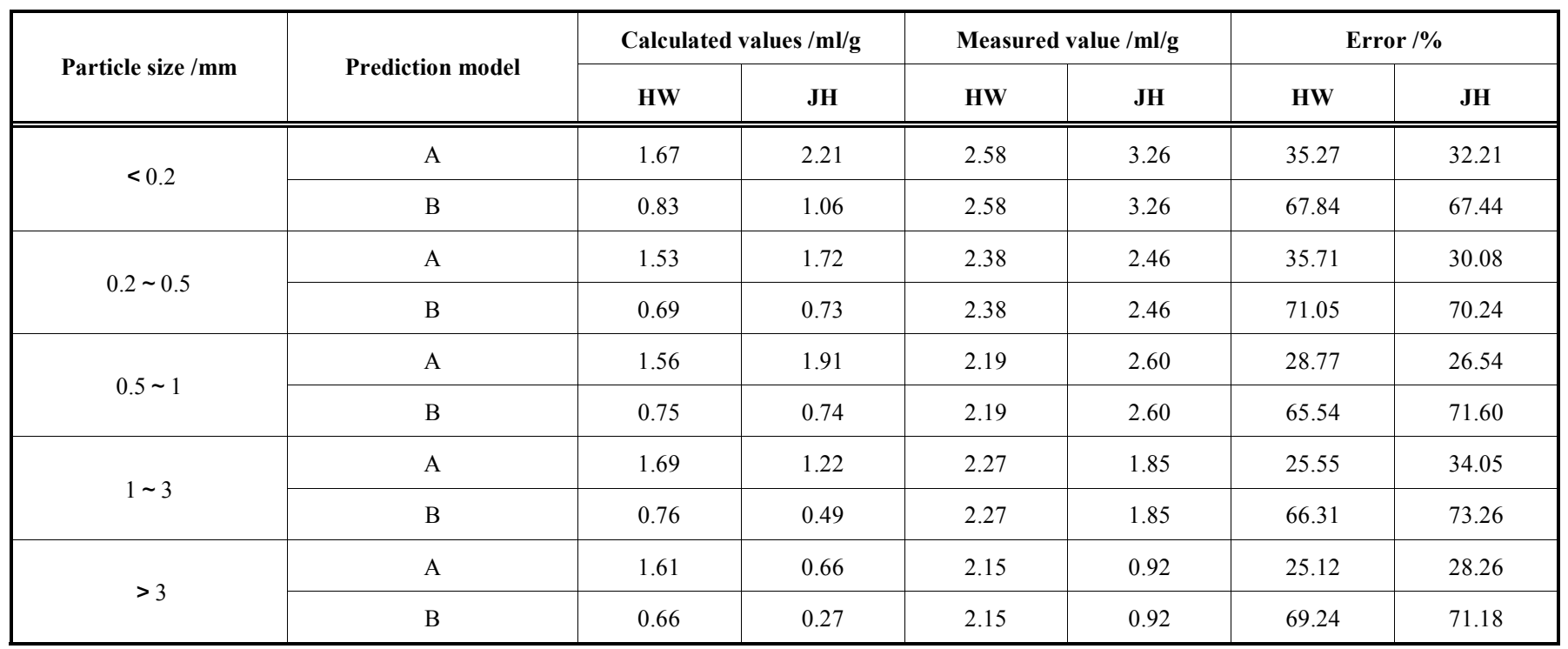

A: $\sqrt{t}$ method, B: power function method.

leads to big error in gas content calculation. By sorting and analyzing all the data of experiment we came to the improved calculation model as followed:

$$
V_{L}=(1+\mathrm{k}) V_{L^{\prime}}^{\prime} \quad V_{L}^{\prime}=V-K \sqrt{\mathrm{t}_{0}+\mathrm{t}}
$$

In the formula:

$V$ L-Real lost gas content during exposed time $\mathrm{t} 0, \mathrm{ml} / \mathrm{g}$; $\mathrm{ml} / \mathrm{g}$

$V_{L}^{\prime}$ - Calculated lost gas content during exposed time t0,

$V$ - Total desorption volume during $\mathrm{t}, \mathrm{ml} / \mathrm{g}$;

t- Desorption time of coal sample, min;

t0- Exposed time of coal sample(it was set to $3 \mathrm{~min}$ in the experiment), $\min$;
K-Undetermined coefficient (it was set to 0.42 according to the extreme-soft and outburst-prone coal sample of Hunan province);

K- Undetermined coefficient.

Before calculating we built the coordinate ("V" is Y label and $\sqrt{\mathrm{t} 0+\mathrm{t}}$ is $\mathrm{X}$ label), put the data into coordinate and then calculate value $V_{L}^{\prime}$ and $V_{L}$ by the least square method.

Calculation result of lost gas content by improved $\sqrt{t}$ method under $1 \mathrm{MPa}$ and $2 \mathrm{MPa}$ equilibrium pressure condition was shown in Table $\mathbf{3}$ (scatter diagram was shown in Fig. 2), according to Table $\mathbf{3}$ and Fig. (2), we can come to the conclusion that the error of lost gas content calculated by improved $\sqrt{\mathrm{t}}$ method is $0.72 \% \sim 9.15 \%$, and the mean error is 
Table 3. Loss gas quantity calculated by improved $\sqrt{t}$ method.

\begin{tabular}{|c|c|c|c|c|c|c|c|c|c|c|c|c|}
\hline \multirow{2}{*}{$\begin{array}{l}\text { Particle size } \\
\qquad / \mathbf{m m}\end{array}$} & \multirow{2}{*}{$\begin{array}{c}\text { Adsorption } \\
\text { equilibrium } \\
\text { pressure /MPa }\end{array}$} & \multirow{2}{*}{$\begin{array}{c}\text { Undetermined } \\
\text { coefficient } \\
/ \mathbf{k}\end{array}$} & \multicolumn{2}{|c|}{$V \mathrm{~L} / \mathrm{ml} / \mathrm{g}$} & \multicolumn{2}{|c|}{$V \mathrm{~L} / \mathrm{ml} / \mathrm{g}$} & \multicolumn{2}{|c|}{$\begin{array}{c}\text { Laboratory } \\
\text { measured value } \\
\text { /ml } / \mathrm{g}\end{array}$} & \multicolumn{2}{|c|}{ Original error $/ \%$} & \multicolumn{2}{|c|}{$\begin{array}{c}\text { Improved error } \\
\qquad / \%\end{array}$} \\
\hline & & & HW & JH & HW & JH & HW & JH & HW & JH & HW & JH \\
\hline \multirow{2}{*}{$<0.2$} & 1 & 0.42 & 1.42 & 1.96 & 2.02 & 2.78 & 1.97 & 2.55 & 27.92 & 23.14 & -2.36 & -9.15 \\
\hline & 3 & 0.42 & 1.67 & 2.21 & 2.37 & 3.14 & 2.58 & 3.26 & 35.27 & 32.21 & 8.09 & 3.74 \\
\hline \multirow{2}{*}{$0.2 \sim 0.5$} & 1 & 0.42 & 1.18 & 1.14 & 1.68 & 1.62 & 1.66 & 1.68 & 28.92 & 32.14 & -0.94 & 3.64 \\
\hline & 3 & 0.42 & 1.53 & 1.72 & 2.17 & 2.44 & 2.38 & 2.46 & 35.71 & 30.08 & 8.71 & 0.72 \\
\hline \multirow{2}{*}{$0.5 \sim 1$} & 1 & 0.42 & 1.20 & 1.11 & 1.70 & 1.58 & 1.75 & 1.46 & 31.43 & 23.97 & 2.63 & -7.96 \\
\hline & 3 & 0.42 & 1.56 & 1.91 & 2.22 & 2.71 & 2.19 & 2.60 & 28.77 & 26.54 & -1.15 & -4.32 \\
\hline \multirow{2}{*}{$1 \sim 3$} & 1 & 0.42 & 0.97 & 0.99 & 1.38 & 1.41 & 1.45 & 1.47 & 33.10 & 32.65 & 5.01 & 4.37 \\
\hline & 3 & 0.42 & 1.69 & 1.22 & 2.40 & 1.73 & 2.27 & 1.85 & 25.55 & 34.05 & -5.72 & 6.36 \\
\hline \multirow{2}{*}{$>3$} & 1 & 0.42 & 1.29 & 0.48 & 1.83 & 0.68 & 1.72 & 0.63 & 25.00 & 23.81 & -6.50 & -8.19 \\
\hline & 3 & 0.42 & 1.61 & 0.66 & 2.29 & 0.94 & 2.15 & 0.92 & 25.12 & 28.26 & -6.33 & -1.87 \\
\hline
\end{tabular}

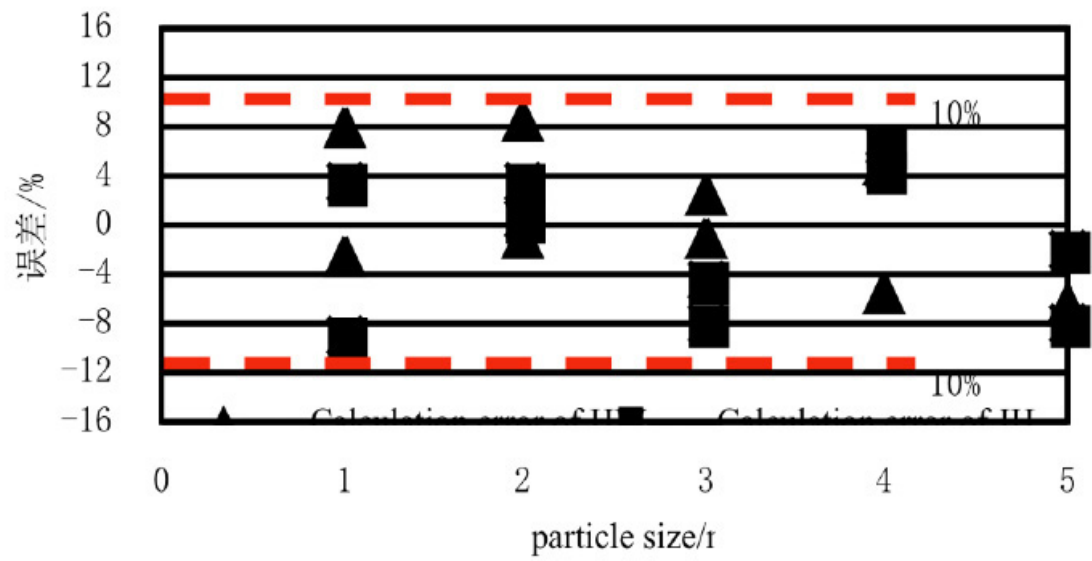

Fig. (2). Scatter of loss gas quantity error calculated by improved $\sqrt{t}$ method.

On the abscissa: $1-<0.2 \mathrm{~mm}, 2-0.2 \mathrm{~mm} \sim 0.5 \mathrm{~mm}, 3-0.5 \mathrm{~mm} \sim 1 \mathrm{~mm}, 4-1 \mathrm{~mm} \sim 3 \mathrm{~mm}, 5->3 \mathrm{~mm}$

Table 4. Lost gas content calculated by improved $\sqrt{\mathrm{t}}$ method (equilibrium gas pressure is $2 \mathrm{MPa}$ ).

\begin{tabular}{|c|c|c|c|c|c|c|c|c|c|}
\hline \multirow{2}{*}{ Particle size /mm } & \multirow{2}{*}{$\begin{array}{c}\text { Undetermined } \\
\text { coefficient/k }\end{array}$} & \multicolumn{2}{|c|}{ UL/ml/g } & \multicolumn{2}{|c|}{ UL/ml/g } & \multicolumn{2}{|c|}{ Measured value /ml/g } & \multicolumn{2}{|c|}{ Error/\% } \\
\cline { 3 - 10 } & & $\mathbf{H W}$ & $\mathbf{J H}$ & $\mathbf{H W}$ & $\mathbf{J H}$ & $\mathbf{H W}$ & $\mathbf{J H}$ & $\mathbf{H W}$ & $\mathbf{J H}$ \\
\hline \hline$<0.2$ & 0.42 & 1.76 & 2.35 & 2.50 & 3.34 & 2.35 & 3.20 & -6.35 & -4.28 \\
\hline $0.2 \sim 0.5$ & 0.42 & 1.52 & 1.74 & 2.16 & 2.47 & 2.37 & 2.40 & 8.93 & -2.95 \\
\hline $0.5 \sim 1$ & 0.42 & 1.38 & 1.29 & 1.96 & 1.83 & 2.10 & 1.73 & 6.69 & -5.88 \\
\hline $1 \sim 3$ & 0.42 & 1.40 & 1.01 & 1.99 & 1.43 & 2.00 & 1.56 & 0.60 & 8.06 \\
\hline$>3$ & 0.42 & 1.65 & 0.59 & 2.34 & 0.84 & 2.15 & 0.79 & -8.98 & -6.05 \\
\hline
\end{tabular}


Table 5. Errors by improved $\sqrt{\mathrm{t}}$ method in coal mine.

\begin{tabular}{|c|c|c|c|c|c|c|c|c|}
\hline Name of mine & Test location & $\begin{array}{c}\text { Lost gas } \\
\text { content } \\
/ \mathbf{m} 3 / \mathbf{t}\end{array}$ & $\begin{array}{c}\text { Desorption } \\
\text { amount/ } \\
\mathrm{m} 3 / \mathbf{t}\end{array}$ & $\begin{array}{c}\text { Gas resi- } \\
\text { dues / m3/t }\end{array}$ & $\begin{array}{c}\text { Gas content } \\
\text { measured } \\
\text { value / } \mathbf{m} 3 / \mathrm{t}\end{array}$ & $\begin{array}{c}\text { Gas pres- } \\
\text { sure/ } \\
\text { MPa }\end{array}$ & $\begin{array}{c}\text { True gas } \\
\text { content / } \\
\text { m3/t }\end{array}$ & Error $/ \%$ \\
\hline Tan jiachong & -150 north alleys & 5.50 & 9.24 & 3.26 & 18.00 & 1.42 & 17.47 & -3.00 \\
\hline Puxi & 2251 alleys & 5.21 & 5.11 & 2.74 & 13.06 & 1.65 & 12.71 & -2.77 \\
\hline
\end{tabular}

Remarks: the true gas content is obtained by calculating though Langmuir formula

$4.91 \%$, it is below $10 \%$. By this improved method the gas content calculation result is nearly to the real value, so it could be used to engineering calculation.

\section{VERIFICATION OF THE IMPROVED METHOD}

In order to verify the improved $\sqrt{\mathrm{t}}$ method in calculating lost gas content of extreme-soft and outburst-prone coal seams, we used it to calculate both in laboratory and coal mines.

\subsection{Verification in Laboratory}

In laboratory we calculated lost gas content of HW and $\mathrm{JH}$ coal samples of different size under $2 \mathrm{MPa}$ equilibrium pressure condition by the improved $\sqrt{\mathrm{t}}$ method, calculation and error analysis result was shown in Table 4. According to Table 4, the error is $0.6 \% \sim 8.98 \%$ and means error is $6.88 \%$, smaller than $10 \%$.

\subsection{Verification in Coal Mines}

In Tan jiachong coal mine and Jiahe coal mine we measured gas pressure precisely and then calculated gas content (it was considered to be real value) with Langmuir formula, meantime we measured gas content by method mentioned before, and finally compare the two result (as shown in Table 5), according to comparison we found the gas content in coal mines calculated by improved $\sqrt{\mathrm{t}}$ method is nearly to the real value, and the biggest error is only $5.24 \%$.

\section{CONCLUSION}

(1) The mean error of lost gas content of HW coal samples calculated by $\sqrt{\mathrm{t}}$ method is $29.68 \%$, and $\mathrm{JH}$ is $28.55 \%$, however, the result is up to $68.33 \%$ and $70.28 \%$ if we use power function method.

(2) Calculation results by $\sqrt{t}$ method and power function method are lower, but the former one is more precise.

(3) By sorting and analyzing lots of experiment data, a new calculation model based on $\sqrt{\mathrm{t}}$ method was found, that is $V_{L}=(1+\mathrm{k}) V_{L}^{\prime}$ and $V_{L}^{\prime}=V-K \sqrt{\mathrm{t}_{0}+\mathrm{t}}$.

(4) We verified the accuracy of the new model which is based on $\sqrt{\mathrm{t}}$ method in both laboratory and coal mines, mean error of calculation result in laboratory is $6.88 \%$ and biggest error in coal mines is $5.24 \%$, they are both below $10 \%$, so it could be used to calculate gas content in all conditions.

\section{CONFLICT OF INTEREST}

The authors confirm that this article content has no conflict of interest.

\section{ACKNOWLEDGEMENTS}

The research of this paper has been sponsored by Science and technology plan projects of Science and Technology Department of Hunan Province (2012SK3308), Open fund projects of Hunan key laboratory on Coal mine safety mining technology (201204).

\section{REFERENCES}

[1] State Administration of Work Safety, Provisions on Prevention and Control of Coal and Gas Outbursts, 2009.

[2] Standardization Administration of the People's Republic of China, The direct method of determining coalbed gas content in the mine [GBT23250-2009]. 2009.

[3] The People's Republic of China coal industry, Determine method of methane adsorption capacity in coal [MT/T752-1997]. 1997.

[4] D.l Chen, and Y. Chen, "Summary of measurement method of gas content," Safety in Coal Mines, vol. 39, no. 2, pp. 79-82, 2008.

[5] J.P. Wei, Y.C. Chen, and Z. Wen, "Study of gas desorption laws of tectonically coal," Safety in Coal Mines, vol. 405, no. 8, pp. 1-3, 2008.

[6] F.U. Xiang, K.J. Wang, T. Yang, "Gas irradiation feature of tectonic coal," Journal of China Coal Society, vol. 33, no. 7, pp. 775779, 2008.

[7] Y. Li, Y. Zhang, and Z. Zhang, "Experimental study on gas desorption of tectonic coal at initial stage," Journal Of China Coal Society, vol. 38, no. 1, pp. 15-20, 2013.

[8] R.M. Barrer, Diffusion in and through solid, Cambridge University Press: England, 1973, pp. 19-51.

[9] K. Winter, and H. Janas, "Gas emission characteristics of coal and methods of determining the desorbable gas content by means of desorbometers," XIV International Conference of Coal Mine Safety Research, 1996.

[10] B.A. Bolt, "Diffusion of carbon dioxide from coal," Fuel, vol. 38, pp. 28-31, 1959.

[11] J. Chen, R. Zhang, and L. Chai, "Research on calculation method of gas loss quantity in sampling process," Safety in Coal Mines, vol. 41, no. 4, pp. 84-86, 2010.

[12] Z. Shang, "Research on calculation method of gas loss quantity in direct measuring process," Safety in Coal Mines, vol. 43, no. 1, pp. $1-4,2012$. 
[13] X. Wang, X. Li, and D. Chen, "Application of coal bed gas content measuring method in jianxin coal mine of fengcheng mine area," Coal Technology, vol. 30, no. 6, pp. 120-122, 2001.

[14] Y. Qin, "Analysis on the question of the geological exploration gas content measurement," Safety in Coal Mines, vol. 42, no. 8, pp. 144-146, 2011.
[15] X. Chen, Z. Wang, L. Wang, "Research on gas loss quantity prediction model in sampling process," Safety in Coal Mines, vol. 44, no. 9, pp. 31-37, 2013

[16] X. Chen, Research on the Gas Desorption Law of the Strong Destruction Coal, Henan University of Science and Technology: JiaoZuo, 2008, pp. 2-4.

Received: September 16, 2014

Revised: December 23, 2014

Accepted: December 31, 2014

(C) Dong-fang et al.; Licensee Bentham Open.

This is an open access article licensed under the terms of the Creative Commons Attribution Non-Commercial License (http://creativecommons.org/licenses/by-nc/3.0/) which permits unrestricted, non-commercial use, distribution and reproduction in any medium, provided the work is properly cited. 